RESEARCH ARTICLE SUMMARY

TECTONICS

\title{
Revised paleoaltimetry data show low Tibetan Plateau elevation during the Eocene
}

sonal precipitation over the Indian foreland, with summer convective rainfall reaching the TP. An intense anticyclonic circulation during summer months induces widespread aridity on the northern part of the Plateau. This peculiar atmospheric circulation, together with intensified water recycling and multiple moisture sources, results in a reversed isotopic lapse rate across the southern flank of the TP, with the most negative $\delta^{18} \mathrm{O}_{\mathrm{w}}$ over northern India and

\author{
Svetlana Botsyun*, Pierre Sepulchre, Yannick Donnadieu, Camille Risi, \\ Alexis Licht, Jeremy K. Caves Rugenstein
}

INTRODUCTION: The uplift history of the Tibetan Plateau (TP) is critical for understanding the evolution of the Asian monsoons and the geodynamic forces involved in collisional orogens. The early topographic history of the TP is uncertain, and the timing of the initiation of uplift remains controversial. The majority of studies that find evidence for an old plateau (as early as the Eocene, $\sim 40$ million years ago) rely on stable isotope paleoaltimetry. This method is based on observations and models that show depletion in heavy oxygen isotopes in rainfall during orographic ascent. Ancient carbonates of the TP record past rainfall isotopes; when available, their isotopic signature can be compared with isotopic lapse rates in order to estimate at what elevation they grew in the past, but the use of this method in deep time has many uncertainties.

RATIONALE: Applying stableisotope paleoaltimetry in greenhouse climates makes the implicit assumption that the factors that control atmospheric distillation and rainfall oxygen isotopic composition $\left(\delta^{18} \mathrm{O}_{\mathrm{w}}\right)$ have remained constant over millions of years. However, the impact of past climate change on $\delta^{18} \mathrm{O}_{\mathrm{w}}$ values is unclear. In particular, for the Eocene, higher atmospheric $\mathrm{CO}_{2}$ concentration $\left(\mathrm{PCO}_{2}\right)$ and markedly different Asian paleogeog-

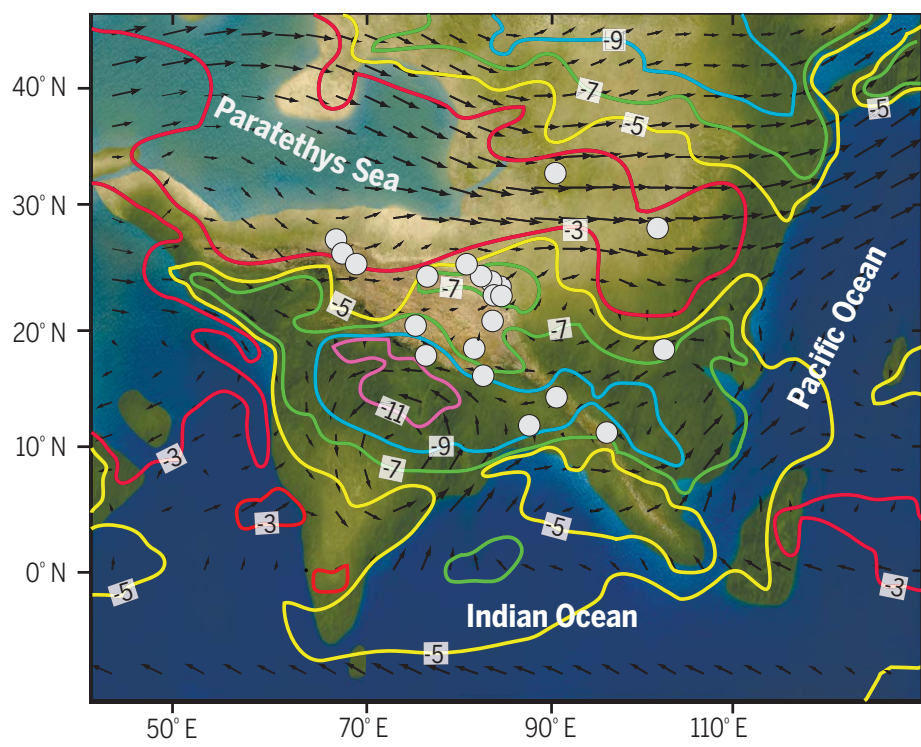

RESULTS: We ran climate simulations with Eocene boundary conditions and varying TP elevation. We accounted for changing $\mathrm{PCO}_{2}$, land surface albedo, orbital variation, and sea-surface temperatures, which potentially cause shifts in $\delta^{18} \mathrm{O}_{\mathrm{w}}$, by changing the relative contribution of different air masses and the local hydrological cycle-the evaporation-
ON OUR WEBSITE

Read the full article at http://dx.doi. org/10.1126/ science.aaq1436 day $\delta^{18} \mathrm{O}_{\mathrm{w}}$ over the Himalayas, which decreases with elevation, driven by orographic rainout following a Rayleigh distillation process. Last, using our simulated temperatures and $\delta^{18} \mathrm{O}_{\mathrm{w}}$, we derived virtual carbonates $\delta^{18} \mathrm{O}$ for different elevation scenarios and compared them with the geological record. Statistical analysis shows that a low TP topography during the Eocene is the scenario that provides the best match between model and data.

CONCLUSION: Our simulations indicate that standard stable isotope paleoaltimetry methods are not applicable in Eocene Asia because of a combination of increased convective precipitation, mixture of air masses of different origin, and widespread aridity. In the Eocene, the presence of a reversed isotopic lapse rate precludes use of any of the previously developed $\delta^{18} \mathrm{O}_{\mathrm{w}}$-elevation relationships for estimating the Eocene elevation of the TP. Rather, a model-data comparison on the carbonates $\delta^{18} \mathrm{O}$ suggests that the TP reached only low to moderate $(<3000 \mathrm{~m})$ elevations during the Eocene, reconciling oxygen isotope data with other proxies of elevation and with geodynamic models that propose a recent (Neogene) uplift. More generally, we suggest that using climate models in conjunction with stable isotope data from the georaphy, including a wide and shallow Paratethys Sea in central China and a latitudinal shift of the southern Tibet margin $\sim 10^{\circ}$ to the south, have been hypothesized to modify the Asian climate and regional $\delta^{18} \mathrm{O}_{\mathrm{w}}$ values. In addition, the carbonate formation temperature is often unknown, increasing the uncertainty in the reconstructed $\delta^{18} \mathrm{O}_{\mathrm{w}}$. to-precipitation ratio and the fractioning between convective and large-scale rainfalls. In our simulations, the south-shifted location of the entire Indian foreland induces strong convection over the southern flank of the TP and a radically different pattern of water recycling compared with that of present day. Our simulations reproduce monsoonlike sea- 
RESEARCH ARTICLE

TECTONICS

\section{Revised paleoaltimetry data show low Tibetan Plateau elevation during the Eocene}

\author{
Svetlana Botsyun ${ }^{1,2 *}$, Pierre Sepulchre ${ }^{1}$, Yannick Donnadieu ${ }^{1,3}$, Camille Risi ${ }^{4}$, \\ Alexis Licht ${ }^{5}$, Jeremy K. Caves Rugenstein ${ }^{6,7}$
}

\begin{abstract}
Paleotopographic reconstructions of the Tibetan Plateau based on stable isotope paleoaltimetry methods conclude that most of the Plateau's current elevation was already reached by the Eocene, $\sim 40$ million years ago. However, changes in atmospheric and hydrological dynamics affect oxygen stable isotopes in precipitation and may thus bias such reconstructions. We used an isotope-equipped general circulation model to assess the influence of changing Eocene paleogeography and climate on paleoelevation estimates. Our simulations indicate that stable isotope paleoaltimetry methods are not applicable in Eocene Asia because of a combination of increased convective precipitation, mixture of air masses, and widespread aridity. Rather, a model-data comparison suggests that the Tibetan Plateau only reached low to moderate (less than $\mathbf{3 0 0 0}$ meters) elevations during the Eocene, reconciling oxygen isotope data with other proxies.
\end{abstract}

B ecause the Tibetan Plateau (TP) is the largest orogen on Earth, its uplift history is critical for understanding the evolution of the Asian monsoon systems and the geodynamic forces involved in continental collisions $(1,2)$. Previous reconstructions have proposed a wide range of paleogeographies for the late Eocene of Tibet, which all accommodate India-Asia plate motion through a combination of Indian plate subduction and Asian shortening and extrusion (3), but the altitude of the TP through time remains disputed (4). Numerous uplift scenarios for the TP have been suggested from a precollision, highly elevated Plateau [for example, 100 million years (Ma) ago] (5) through stepwise uplift since initial collision ( $~ 55 \mathrm{Ma}$ ago) (6) to more recent rapid uplift, particularly of the northern and eastern TP (<8 Ma ago) (7). Although any of these uplift scenarios are possible, they imply different geodynamic mechanisms and climate responses.

${ }^{1}$ Laboratoire des Sciences du Climat et de l'Environnement (LSCE)/Institute Pierre Simon Laplace (IPSL), Commissariat á l'Énergie Atomique et aux Énergies Alternatives (CEA)CNRS-Université de Versailles Saint-Quentin-en-Yvelines (UVSQ), Université Paris-Saclay, Gif-sur-Yvette, France. 2Department of Geosciences, University of Tübingen, Tübingen, Germany. ${ }^{3}$ Aix-Marseille Université, CNRS, Institut pour la Recherche et le Développement (IRD), Collège de France, Centre de Recherche et d'Enseignement de Géosciences de l'Environnement (CEREGE), Aix-en-Provence, France. ${ }^{4}$ Laboratoire de Météorologie Dynamique, IPSL, Sorbonne Université, CNRS, Paris, France. ${ }^{5}$ Department of Earth and Space Sciences, University of Washington, Seattle, WA, USA. ${ }^{6}$ Department of Earth System Science, Stanford University, Stanford, CA, USA. ${ }^{7}$ Department of Earth Sciences, ETH-Zürich, Zürich, Switzerland.

*Corresponding author. Email: svetlana.botsyun@uni-tuebingen.de
The elevation of the TP since the Eocene as reconstructed in stable isotope paleoaltimetry studies is close to modern values $(>4000 \mathrm{~m}$ ) (8-10). However, other lines of evidence from paleobotany $(11,12)$ and paleontology $(13,14)$ suggest much lower elevations of the TP in the past. Improved constraints on the early topographic history of the TP are critical to better understand the geodynamic evolution of IndiaEurasian collision and its consequences on the climate system-namely, the Asian monsoon onset.

Stable isotope paleoaltimetry is based on the observed and theoretically predicted decrease of precipitation water $\delta^{18} \mathrm{O}\left[\delta^{18} \mathrm{O}_{\mathrm{w}}\right.$, expressed in per mil (\%o)] with increasing elevation across mountain ranges (15). In the Himalayas and southern Tibet, the present-day isotopic lapse rate is $\sim-2.8 \% / \mathrm{km}(16)$, which is in agreement with distillation models that predict decreasing $\delta^{18} \mathrm{O}_{\mathrm{w}}$ in response to decreasing atmospheric humidity and temperature during orographic ascent (15). This altitude effect is archived in the $\delta^{18} \mathrm{O}$ of continental carbonates $\left(\delta^{18} \mathrm{O}_{\mathrm{c}}\right)$, offset from $\delta^{18} \mathrm{O}_{\mathrm{w}}$ by a fractionation factor that depends on the carbonate formation temperature (17). Stable isotope paleoaltimetry studies commonly provide $\delta^{18} \mathrm{O}_{\mathrm{c}}$ at sites of unknown elevation; make assumptions about the temperature at the site, the near-sea level $\delta^{18} \mathrm{O}_{\mathrm{w}}$, and the atmospheric relative humidity; and from this, reconstruct the paleoelevation by using modern empirical or modeled lapse rates $(15,16)$.

However, stable isotope paleoaltimetry relies on the key assumption that the main atmospheric factors that control atmospheric distillation and air mass $\delta^{18} \mathrm{O}$ values have remained constant over millions of years. The impact of past climate change-including changes in lapse rates (18), sources of precipitation (9), and in monsoonal regime (19)-on $\delta^{18} \mathrm{O}_{\mathrm{w}}$ is uncertain but has been hypothesized to affect $\delta^{18} \mathrm{O}_{\mathrm{w}}$ over the TP (20). In addition, carbonate growth temperature is often unknown, increasing the uncertainty in the reconstructed $\delta^{18} \mathrm{O}_{\mathrm{w}}(17)$. All these factors may importantly bias deep-time paleoelevation estimates, particularly during the Eocene Greenhouse world. Higher atmospheric $\mathrm{CO}_{2}$ concentration $\left(\mathrm{PCO}_{2}\right)$ at that time (21) and markedly different Asian paleogeography, with a wide and shallow Paratethys Sea in central China (22) and a latitudinal shift of the southern Tibetan margin $\sim 10^{\circ}$ to the south (23), might have substantially modified the Asian hydrological cycle $(24,25)$.

We tested the impact of late Eocene paleogeography and topography variations on water vapor and precipitation $\delta^{18} \mathrm{O}$ using an isotopeenabled version of the LMDZ atmospheric circulation model and compared simulated $\delta^{18} \mathrm{O}_{\mathrm{c}}$ values with previously published data. LMDZiso properly simulates atmospheric dynamics 
and reproduces rainfall and $\delta^{18} \mathrm{O}_{\mathrm{w}}$ patterns consistent with present-day data over Asia, including the substantial depletion that occurs across the Himalayan flanks and the stark southto-north positive gradient in $\delta^{18} \mathrm{O}_{\mathrm{w}}$ across the Plateau (Fig. 1, A and B). In order to fully account for uncertainties regarding our knowledge of Asian paleogeography during the Eocene, we varied the elevation of the TP, the latitude of the TP, and the land-sea mask (Fig. S1). Additionally, we accounted for changing $\mathrm{PCO}_{2}$, land surface albedo, orbital variation, and sea-surface temperatures. These variables potentially cause shifts in $\delta^{18} \mathrm{O}_{\mathrm{w}}$ by changing the relative contri- bution of different air masses and the local hydrological cycle (26-28).

\section{Eocene Asian climate and water $\delta^{18} 0$}

Simulated Eocene large-scale circulation is characterized by monsoonlike seasonal precipitation over the Indian foreland (fig. S2). By contrast, over the TP and over central Asia, westerlies more intense than those of today interacted with large-scale atmospheric subsidence (figs. S2 and S3), causing widespread aridity (Fig. 1C and fig. S2). The onset of an anticyclonic circulation during summer months over the eastern part of the TP (Movie 1) induces intense westerlies and easterlies at each border of the TP. This feature is in stark contrast with the modern simulations, in which the southern TP receives a greater proportion of precipitation from air masses originating in the Bay of Bengal and propagating northward (Movie 1). These processes occur across all of our different paleogeography and paleotopography scenarios. High rainfall over the Indian foreland (Fig. 1, C and D) decreases $\delta^{18} \mathrm{O}_{\mathrm{w}}$ from the southern tip of India ( - -4\% $)$ to a minimum at $15^{\circ} \mathrm{N}$ over the Indian foreland (from -8 to $-11 \%$, depending upon TP topography) (Fig. 2 and fig. S2). The multiple sources feeding precipitation in the southern part of
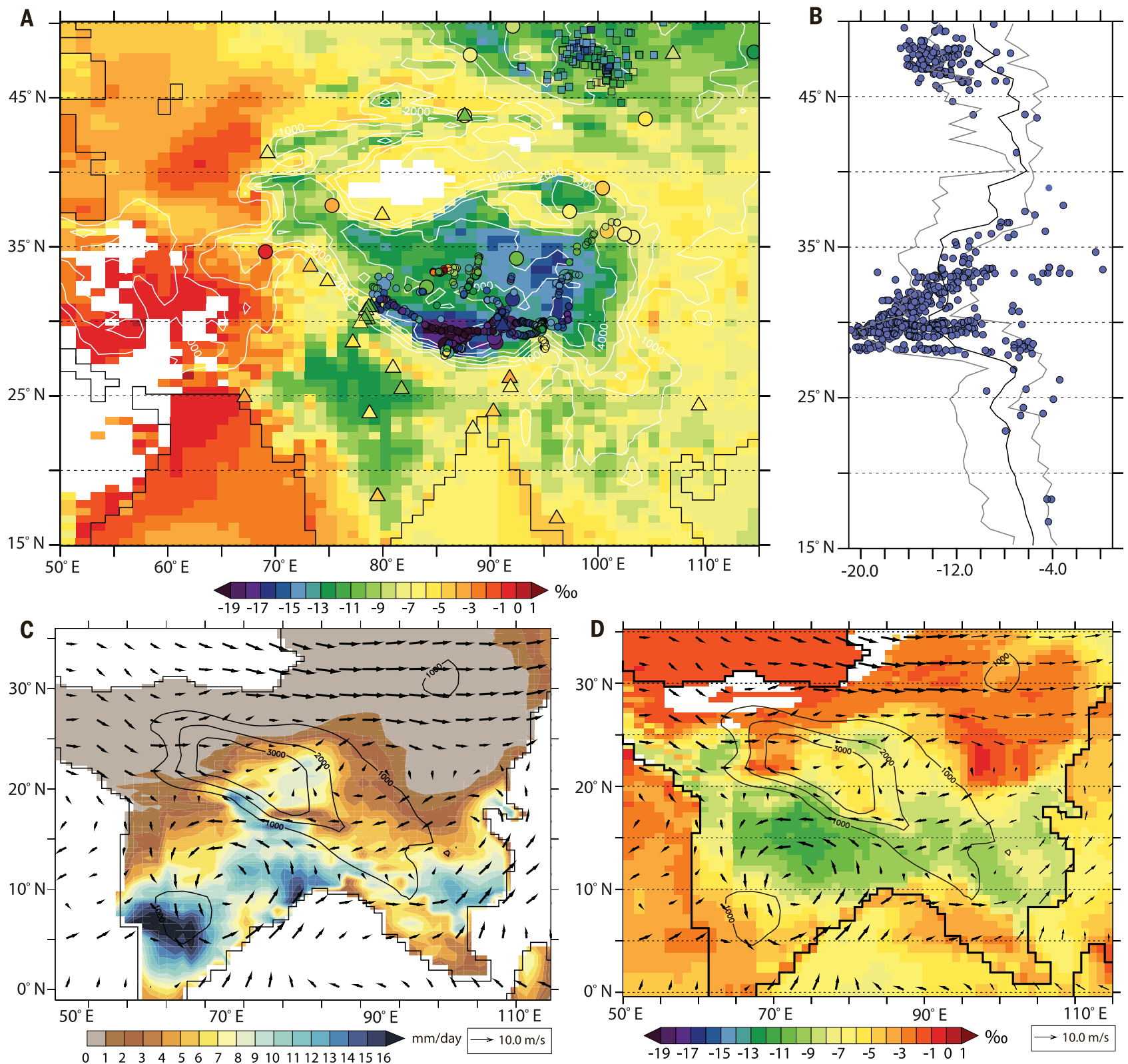

Fig. 1. Present-day and Eocene simulations. (A) Simulated MJJAS precipitation-weighted present-day $\delta^{18} \mathrm{O}_{w}$. Triangles show $\delta^{18} \mathrm{O}_{\mathrm{w}}$ from GNIP stations (70), circles represent $\delta^{18} \mathrm{O}$ in streams, rivers, and springs from [(37) and references therein] compilation. (B) The $\delta^{18} \mathrm{O}$ south-north profile, averaged between $70^{\circ} \mathrm{E}$ and $90^{\circ} \mathrm{E}$. Gray lines indicate minimum and maximum model $\delta^{18} \mathrm{O}_{\mathrm{w}} 70^{\circ} \mathrm{E}$ and $90^{\circ} \mathrm{E}$. (C and D) Simulated Eocene precipitation and isotopic patterns. (C) LMDZ-simulated MJJAS precipitation amount (millimeters per day), and (D) MJJAS precipitation-weighted $\delta^{18} \mathrm{O}_{\mathrm{w}}(\%)$ and wind velocities (meters per second) for the Eocene (EOC-L) experiment. 
India explain the absence of a correlation between the rainfall and the value of $\delta^{18} \mathrm{O}_{\mathrm{w}}$ in the region (Movie 1). Conversely, more negative $\delta^{18} \mathrm{O}_{\mathrm{w}}$ values over the northern part of the Indian continent arise from distillation processes as specific humidity decreases as air masses progress northward across India owing to high precipitation values. In addition, extremely arid
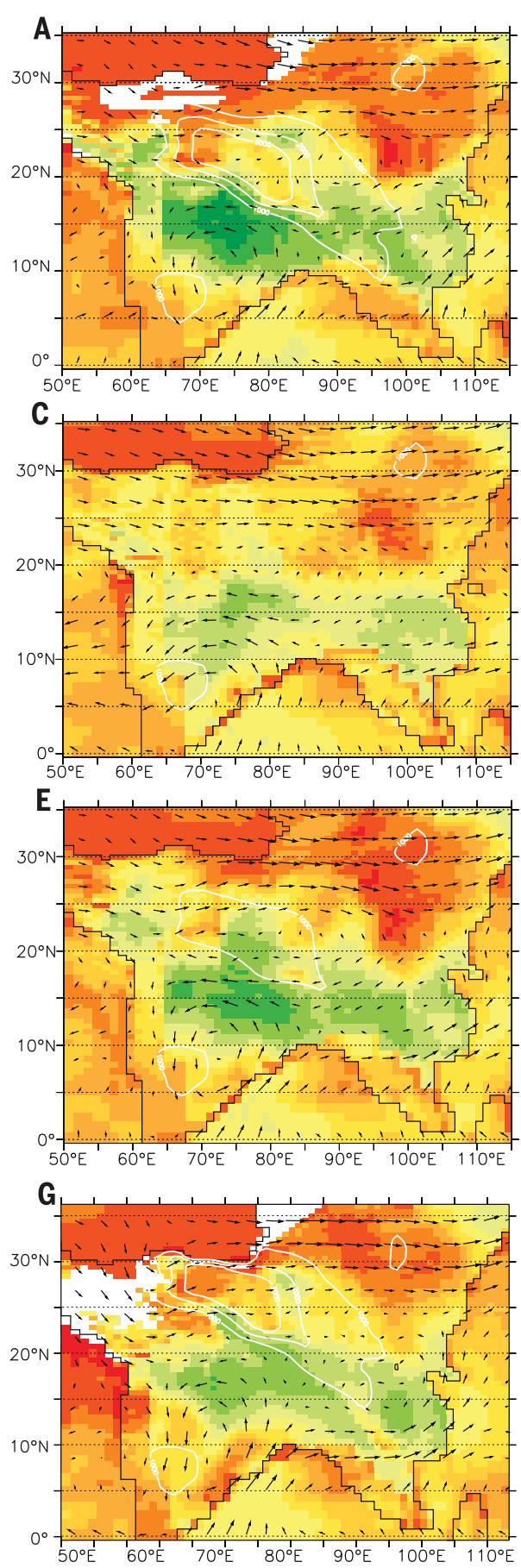

B

environments $(<0.5 \mathrm{~mm} /$ day $)$ over the northern TP and central Asia are associated with higher $\delta^{18} \mathrm{O}_{\mathrm{w}}$ values (from -3 to $-1 \%$ ) (Fig. $1, \mathrm{C}$ and $\mathrm{D}$ ). The most surprising and counterintuitive result in our Eocene simulations is an isotopic gradient across the southern flank of the TP, with $\delta^{18} \mathrm{O}_{\mathrm{w}}$ values ranging from $-8 \%$ o at the foot of the TP to $-5 \%$ at the top of the southern flank of the TP.

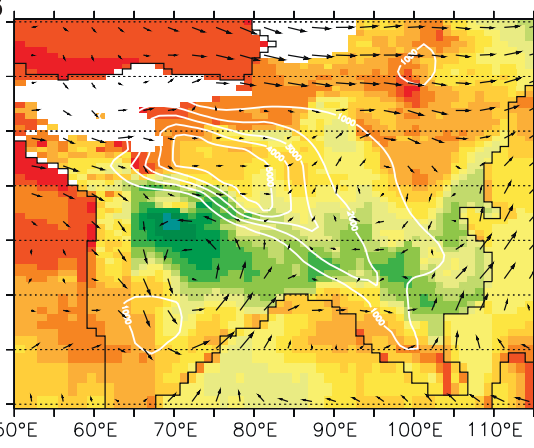

\section{D}
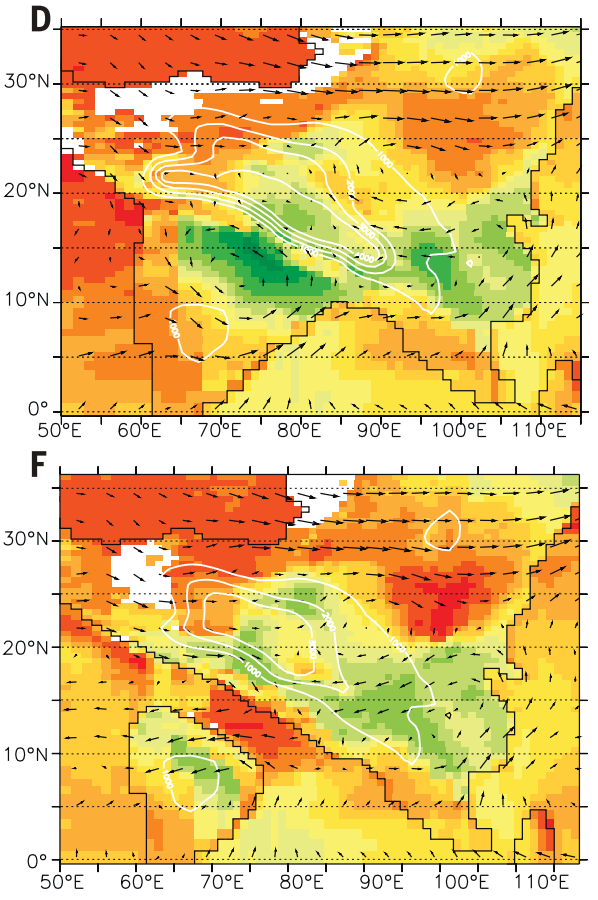

H

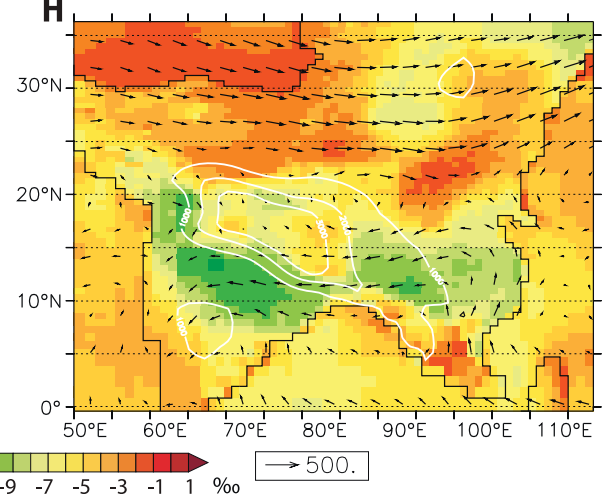

Fig. 2. Precipitation-weighted MJJAS $\delta^{18} \mathrm{O}_{w}$ in simulations. (A) EOC-L. (B) EOC-XL. (C) EOC-S. (D) EOC-Him. (E) EOC-M. (F) EOC-sea. (G) EOC-North. (H) EOC-South. Vectors show MJJAS vertically integrated moisture transport (kilograms per meter per second).

Such a gradient is at odds with modern observed and simulated values that depict a decrease in $\delta^{18} \mathrm{O}_{\mathrm{w}}$ from -8 to $-18 \%$ o as altitude increases on the southern flank of the TP (Fig. 2 and fig. S4). The combination of changes in water recycling and the source of air masses explains the reversal of the isotopic lapse rate during orographic ascent in the Eocene.

\section{Back-trajectory analysis}

Our back-trajectory analysis confirms that in the Eocene, sites across the TP are influenced by multiple air masses that originate from both the Indian Ocean and the Paratethys Sea (Fig. 3 and Movie 1). In detail, stronger westerlies during the Eocene are divided between a southern branch following the Himalayan flanks and a northern branch that deviates to the south and joins the easterlies around $95^{\circ} \mathrm{E}$ (Movie 1 ). The presence of multiple air masses over the Eocene southern TP invalidates two common assumptions $(29,30)$ in stable isotope paleoaltimetry: that (i) southern TP sites receive moisture from a single air mass and (ii) air masses progress over the southern margin and onto the TP, permitting the resulting $\delta^{18} \mathrm{O}_{\mathrm{w}}$ to be treated as a Rayleigh distillation process. Instead, $\delta^{18} \mathrm{O}_{\mathrm{w}}$ over the southern TP appears to be a mixture of multiple air masses having followed along-strike trajectories (eastward and westward winds). Therefore, the assumption of Rayleigh distillation along a single air mass trajectory cannot be used to explain $\delta^{18} \mathrm{O}_{\mathrm{w}}$ patterns over elevated parts of the Eocene topography. Our modeling results are also supported by present-day satellite observations showing that mixing of various air masses tends to induce higher $\delta^{18} \mathrm{O}_{\mathrm{w}}$ than a purely Rayleigh regime (31).

\section{Evaporation to precipitation ratio and precipitation regimes}

The south-shifted location of the Eocene TP induces strong convection over its southern flank and a radically different pattern of water recycling compared with the modern pattern (Fig. 4). These features persist even in a scenario in which the TP has been latitudinally shifted (fig. S5). Our present-day simulation reproduces the large decrease in convective precipitation that exists from the Indian foreland up to the southern flank of the TP [evaporation/ precipitation ratio $(\mathrm{E} / \mathrm{P})$ diminishes along the same transect] (Fig. 4A). However, during the Eocene, convective precipitation (CP) prevails over large-scale precipitation (LSP) (CP/LSP > 1), with no clear decrease in $\mathrm{E} / \mathrm{P}$ over this region (Fig. 4B and fig. S5). The negligible decrease in $\delta^{18} \mathrm{O}_{\mathrm{w}}$ in the Eocene between the Indian foreland and the southern flank of the TP together with high convective precipitation rate are therefore consistent with observational and modeling studies (32-34) that show that stratiform precipitation regimes are associated with more depleted isotopic values than convective regimes. An additional simulation using a TP of the equivalent elevation as today for the Eocene does not change zonal profiles of $\mathrm{E} / \mathrm{P}$ 

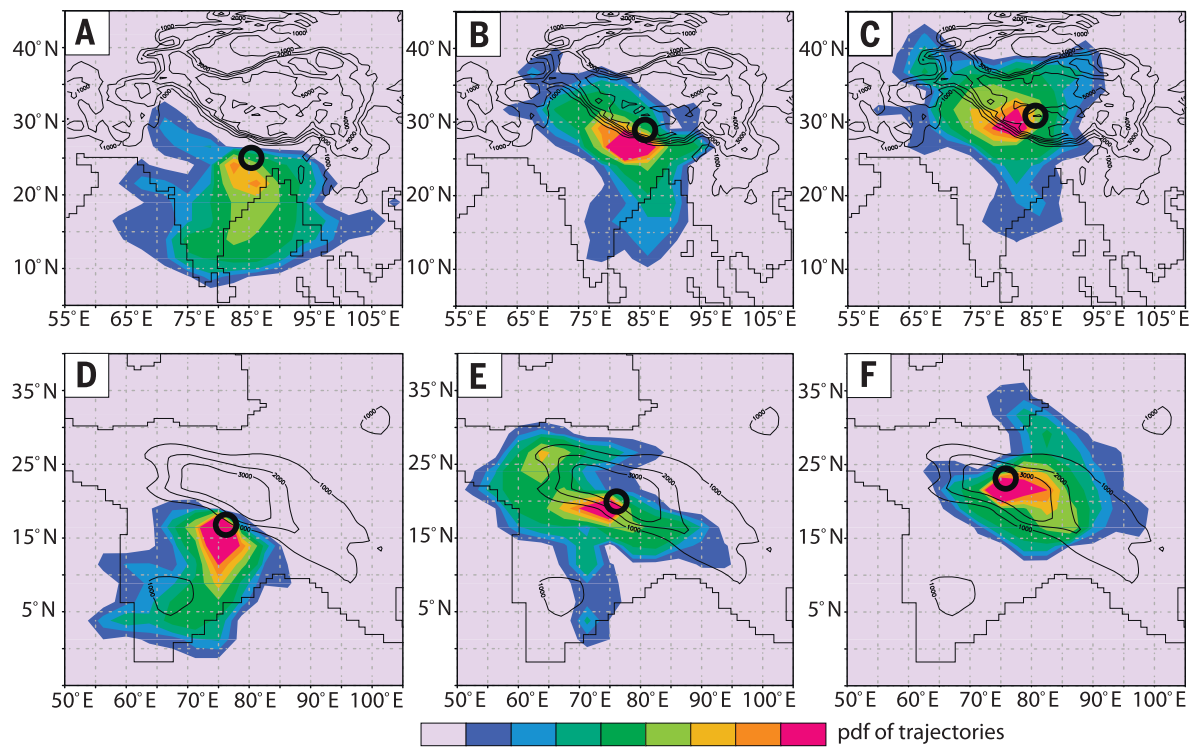

Fig. 3. Back trajectory analysis for present-day (CTR) and Eocene winds. (A to F) The probability distribution of air masses along back trajectories for each of the six points for $[(A)$ to $(C)]$ CTR and [(D) to (F)] EOC-L. Back trajectories are calculated daily from May to September at $900 \mathrm{hPa}$ level, backward for 6 days each, starting from the black circle.

and CP/LSP, suggesting that our hypothesized mechanism to explain reverse isotopic gradients in the Eocene over the southern flank of the TP is robust.

\section{Reversed Eocene isotopic lapse rate}

The increased convective precipitation rates and multiple air masses over the southern TP result in a latitudinal dipole in $\delta^{18} \mathrm{O}_{\mathrm{w}}$, with low $\delta^{18} \mathrm{O}_{\mathrm{w}}$ over the India foreland and higher $\delta^{18} \mathrm{O}_{\mathrm{w}}$ over the TP. This dipole creates an apparent positive isotopic lapse rate across the southern edge of the TP, with increased $\delta^{18} \mathrm{O}_{\mathrm{w}}$ as elevation increases south to north. This positive isotopic lapse rate is a feature of all Eocene simulations, regardless of the prescribed topography, of the latitudinal position of the TP, and of the position of the coastline (Fig. 2). Furthermore, this pattern is opposite to the expected $\delta^{18} \mathrm{O}_{\mathrm{w}^{-}}$ elevation relationship derived from Rayleigh distillation and driven by orographic rainout, which predicts that $\delta^{18} \mathrm{O}_{\mathrm{w}}$ should decrease with elevation (15). Flat isotopic lapse rates are found today in areas of high convective precipitation, such as Ethiopia and Kenya (35) because of convective instability over the region that produces enriched $\delta^{18} \mathrm{O}$ values at altitude. Similar negligible isotopic lapse rates have also been observed in the Andes (36). For the Eocene, this unusual isotopic lapse rate precludes use of any of the previously developed $\delta^{18} \mathrm{O}_{\mathrm{w}}$-elevation relationships for the Eocene TP.

\section{Discussion and comparison with data}

For the purpose of a model-data comparison, we derived virtual $\delta^{18} \mathrm{O}_{\mathrm{c}}$ values using simulated $\delta^{18} \mathrm{O}_{\mathrm{w}}$ and surface temperatures and compared these derived values with measured $\delta^{18} \mathrm{O}_{\mathrm{c}}$ from previous studies (Table 1 and Figs. 5, A and B, and 6). The $\delta^{18} \mathrm{O}_{\mathrm{c}}$ data show a reasonable agreement with the simulated south-north isotopic gradient in $\delta^{18} \mathrm{O}_{\mathrm{c}}$ for the Eocene experiments (Figs. 5, A and B, and 6). However, simulations with relatively low Asian topography (EOC-S and EOC-M) are a better fit, according to a ranking of the model simulations based on the sum of squared residuals (Fig. 5C). The large uncertainties in the $\delta^{18} \mathrm{O}_{\mathrm{c}}$ data preclude any precise paleoaltimetry estimates but do allow us to discriminate between different paleoelevation scenarios. In simulations with higher TP topography, $\delta^{18} \mathrm{O}_{\mathrm{c}}$ data are systematically more negative than simulated $\delta^{18} \mathrm{O}_{\mathrm{c}}$ values (Figs. $5 \mathrm{~A}$ and 6). A decomposition of the effects on $\delta^{18} \mathrm{O}_{\mathrm{c}}$ values shows that this discrepancy is mainly due to the decrease in temperature over the TP as elevation increases because of adiabatic cooling (figs. S7 to S9). Lower carbonate formation temperatures result in less negative $\delta^{18} \mathrm{O}_{\mathrm{c}}$ values over the TP. This effect is enhanced by more intense rainfall over the Indian foreland associated with more depleted $\delta^{18} \mathrm{O}_{\mathrm{w}}$ values (figs. S2 and S3) as TP elevation increases. These two mechanisms reinforce the positive isotopic lapse rate at the southern edge of the TP, resulting in increased $\delta^{18} \mathrm{O}_{\mathrm{c}}$ with increasing elevation.

Despite uncertainties in our modeling approach (Materials and methods), our simulations highlight (i) the permanence of a latitudinal $\delta^{18} \mathrm{O}_{\mathrm{w}}$ dipole in agreement with conclusions from recent studies $(37,38)$ and (ii) the limit of standard atmospheric distillation models based on modern calibrations. We show that most of the assumptions that underlie stable isotope paleoaltimetry-such as commonly used modern temperature lapse rates, single and in-
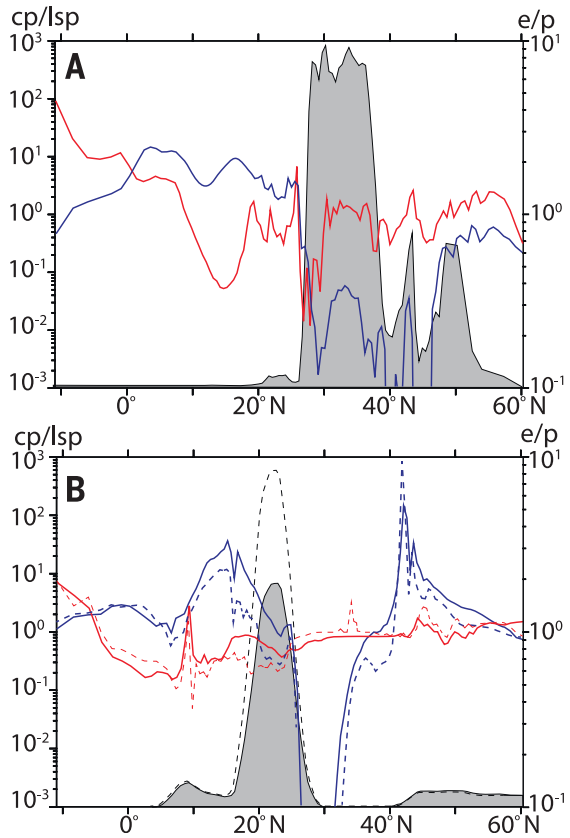

Fig. 4. Hypothesized mechanisms that drive differences between Eocene and presentday $\delta^{\mathbf{1 8}} \mathbf{O}_{\mathbf{w}}$ ( $\mathbf{A}$ and $\left.\mathbf{B}\right)$ The ratio between convective precipitation and large-scale precipitation (CP/LSP, blue lines) and the ratio between evaporation and precipitation (E/P, red lines) along south-north TP cross sections for (A) CTR and (B) Eocene experiments. In (B), dashed lines indicate CP/LSP and E/P for the EOC-XL experiment, and the solid line indicates the same for the EOC-L experiment. Stratiform precipitation is mimicked in the model with large-scale precipitation. Gray shading indicates the topography for the corresponding simulation. Profiles are averaged between $85^{\circ} \mathrm{E}$ and $90^{\circ} \mathrm{E}$ for the CTR case and between $73^{\circ} \mathrm{E}$ and $78^{\circ} \mathrm{E}$ for the Eocene cases.

variant moisture sources, and similar convective precipitation activity-are not valid for the Eocene TP. By contrast, our simulations suggest that previously published $\delta^{18} \mathrm{O}_{\mathrm{c}}$ are more compatible with modest Eocene TP elevations (not higher than $3000 \mathrm{~m}$ ). These estimates reconcile stable isotopic paleoaltimetry estimates with alternative paleontological $(13,14)$ and paleobotanical $(11,12)$ data. Our results imply that substantial uplift (>2000 m) of at least some parts of the TP could have occurred after the Eocene. The complexity of atmospheric processes within greenhouse climates, combined with differing paleogeographies, highlight the necessity of using dedicated climate simulations for interpreting $\delta^{18} \mathrm{O}_{\mathrm{c}}$ data.

\section{Materials and methods Numerical modeling approach}

In order to assess spatial and temporal variations of climatic parameters and the isotopic composition of vapor and precipitation, we use the LMDZ-iso Atmospheric General Circulation 
model (AGCM) (39), a derivative of LMDZ (40). LMDZ was developed at Laboratoire de Météorologie Dynamique (LMD), Paris, France, and is the atmospheric component of the In- stitute Pierre Simon Laplace (IPSL) Earth System Model (ESM) (40), which participates in the Coupled Model Intercomparison Project (CMIPs) program (41). LMDZ incorporates many processes decomposed into a dynamical core, calculating the numerical solutions of general equations of atmospheric dynamics, and a physical part, calculating the details of the climate in each grid

Table 1. Compilation of measured Eocene $\delta^{\mathbf{1 8}} \mathbf{O}_{\mathbf{c}}$ from published materials. Corresponding sample sites, geographic locations are provided in fig. S6 $(8,10,13,24,57-66) . \delta^{18} \mathrm{O}_{\mathrm{c}}$ are reported relative to V-PDB. We report the minimum measured values for lacustrine/biotic data and minimum and averaged values for paleosols. Numbers in parentheses are average values for paleosols. Dashes indicate absence of corresponding data in the original study. For $\delta^{18} \mathrm{O}_{\mathrm{c}}$, dashes are shown where 1 SD calculation is not applicable. PETM, Paleocene-Eocene Thermal Maximum; Min, minimum.

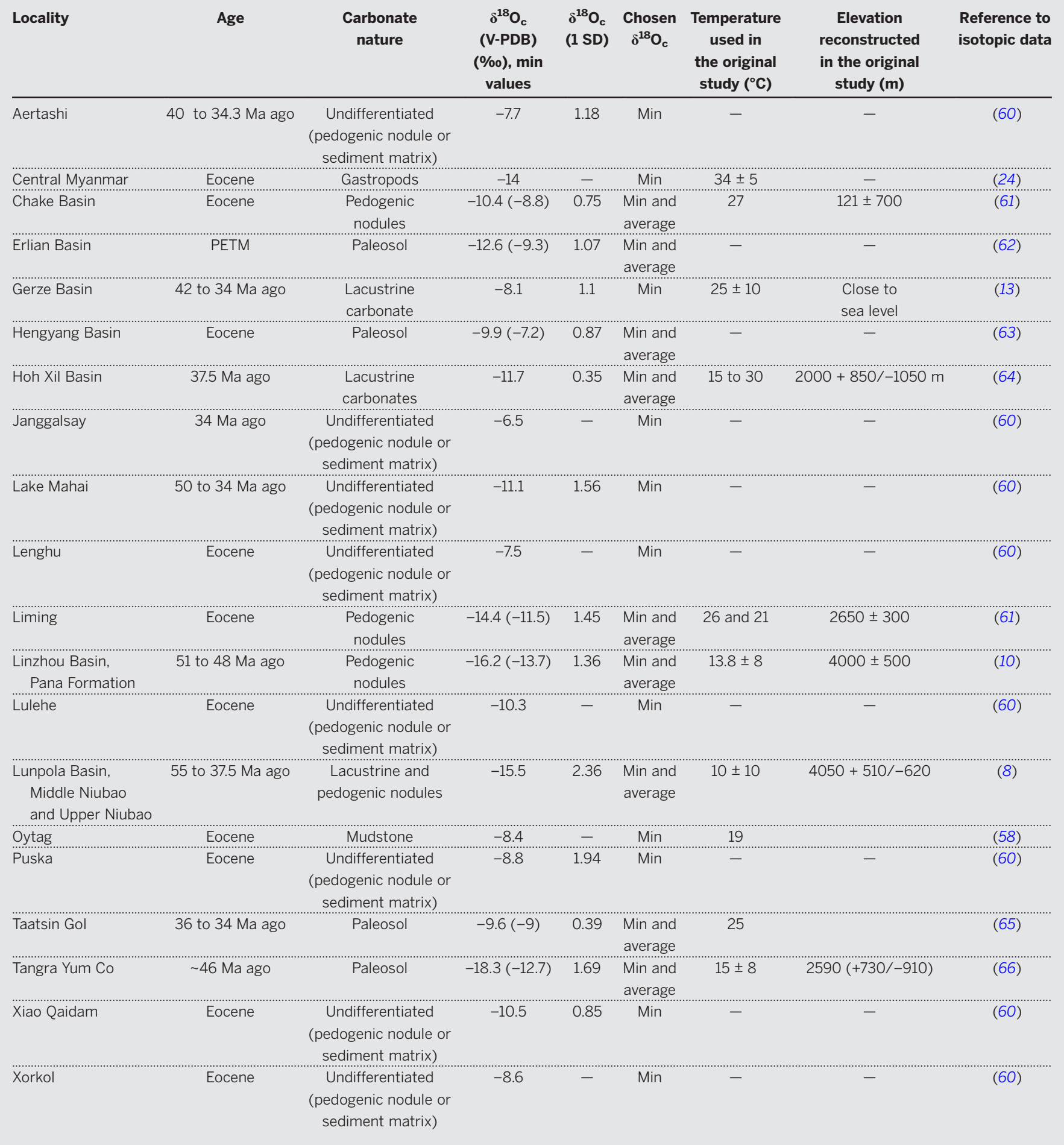


point and containing parameterizations for processes such as the effects of clouds, convection, and orography.

In the version of LMDZ used in this work, the land surface is represented as a simple bucket model, and land surface evaporation is calculated as a single flux: no distinction is made between transpiration, bare soil evaporation, or evaporation of intercepted water by the canopy. However, despite these limitations, the ability of this model to simulate atmospheric dynamics and reproduce rainfall patterns over Asia has been demonstrated in numerous studies $(20,24,42-44)$.

LMDZ-iso represents isotopic processes associated with all phase changes and is documented in (39). The implementation of water isotopes in the convection scheme is described in (45). Water species are transported and mixed passively by large-scale advection (Van Leer advection scheme (46)) and various air mass fluxes. Equilibrium fractionation coefficients are calculated after Merlivat and Nief (47) and Majoube (48) and kinetic effects are taken into account following Merlivat and Jouzel (49) and Jouzel and Merlivat (50). The model takes into account the evolution of the composition of both the rain and surrounding vapor as raindrops re-evaporate (45). However, the model does not account for raindrop size during evaporation as described in Lee and Fung (51).

Here, we use a model configuration with 144 grid points in longitude, 142 in latitude, 39 vertical layers, and a stretchable grid (40) that permits greater regional spatial resolution and yields an average resolution of $\sim 50 \mathrm{~km}$ over central Asia (fig. S10). We force LMDZ-iso with realistic sea-surface temperatures (SSTs) simulated by FOAM (52) and by realistic albedo and roughness values, obtained with the vegetation distribution simulated by the biophysics vegetation model LPJ (fig. S11) (53). We choose this approach rather than (i) using LMDZ-iso with pre-industrial boundary conditions because it permits accounting for the greenhouse gases concentration and related changes in SSTs and (ii) use of a fully coupled GCM, because stable isotopes have not been implemented yet in the IPSL ESM, and present-day calculation capabilities do not allow performing fully coupled experiments in high resolution with the isotopes implementation. We should note, however, that FOAM and similar coarse resolution models (for example, MPIOM, T31) have been successfully applied in many other paleoclimate studies (54). In order to show the capability of the FOAM model to simulate climate, we provide here a rough comparison between the SST and the field data [see the data compilation in (55)] for the Late Eocene, from 38 to $34 \mathrm{Ma}$ (fig. S12).
As in similar recent climate model studies (56), we find that our simulation fits some of the data but not all and that our latitudinal gradient remains too steep when compared to data. We stress that this is a crude comparison as we include data from a long time interval (Late Eocene) during which global climate changes substantially.

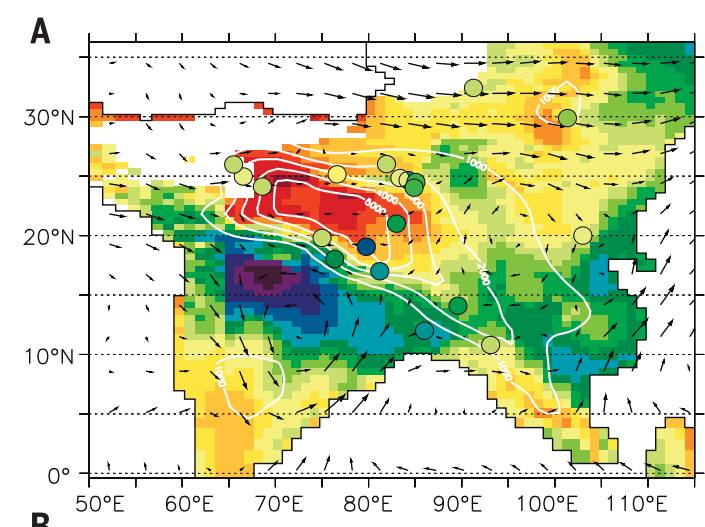

\section{B}

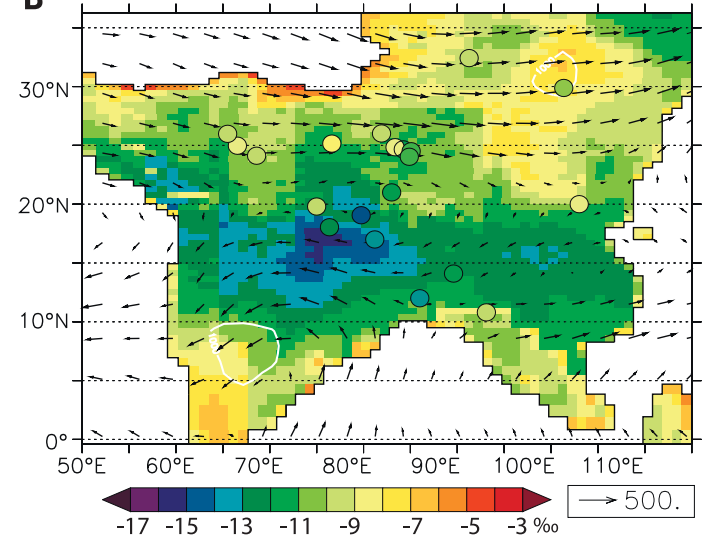

C

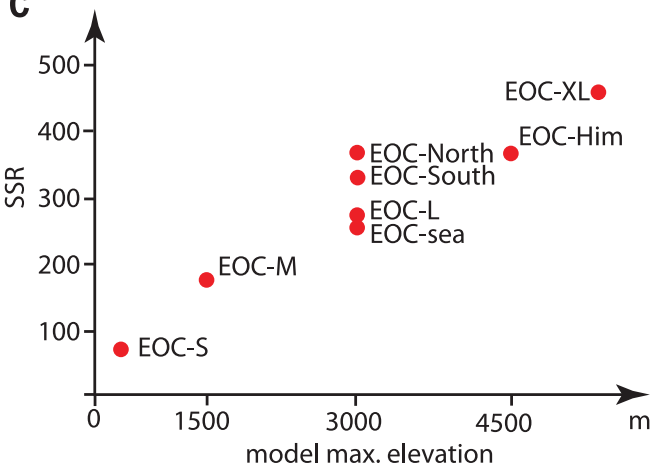

Fig. 5. Model-data comparison for the Eocene. (A and B) Maps of $\delta^{18} \mathrm{O}_{c}$ calculated from model-simulated MJJAS precipitation-weighted $\delta^{18} \mathrm{O}_{\mathrm{w}}$ and model MJJAS mean temperatures for (A) EOC-XL and (B) EOC-S experiments. Points indicate measured $\delta^{18} \mathrm{O}_{\mathrm{c}}$ from published studies (Materials and methods and Table 1), consisting of the most negative values for lacustrine carbonates and average values for paleosols. (C) The sum of squared residuals (SSR) for the Eocene simulations ( $y$ axis) against modeled TP elevation (Materials and methods). The best model-data fit is obtained when SSR is minimized [cases with relatively low Asian topography (EOC-S and EOC-M)].

\section{Experimental design}

We provide experiments depicting both presentday and Eocene climate. For the Eocene experiments, we use the Eocene paleogeography reconstruction of Licht et al. 2014 (24), which includes a southward shift of the Himalayan front, and a large Paratethys Sea to the north of the TP. To understand the role of topography on Eocene climate and the distribution of $\delta^{18} \mathrm{O}_{\mathrm{c}}$, we perform a series of experiments by varying the elevation of the TP. The Eocene TP is as high as $3500 \mathrm{~m}$ in the initial reconstruction (EOC-L simulation) (fig. S1D) (24). The elevation is increased to $5000 \mathrm{~m}$ in the EOC-XL simulation (fig. $\mathrm{S} 1 \mathrm{E})$, reduced to $1750 \mathrm{~m}$ in the EOC-M simulation (fig. S1C) and lowered to $200 \mathrm{~m}$ in the EOC-S simulation (fig. S1B). Additionally, we modify the TP geometry to obtain steep, narrow mountains analogous to the present-day Himalayas over the southern flank of the elevated topography in the EOC-Him experiment (fig. S1F). Lastly, we perform a series of complementary experiments to test different possible Eocene paleogeographies for the studied area: (i) with the TP moved to the south, EOCSouth experiment (fig. S1G); (ii) to the north, EOC-North experiment (fig. S1H); and (iii) with a water body over northern India, EOC-sea experiment (fig. S1J).

For all Eocene simulations, we use $P_{\mathrm{CO}_{2}}$ of $1120 \mathrm{ppm}$, which lies within published estimates (21), and identical SSTs to isolate the effect of topography on atmospheric dynamics and $\delta^{18} \mathrm{O}_{\mathrm{w}}$. We perform one additional experiment with the Eocene paleogeography with pre-industrial $P_{\mathrm{CO}_{2}}(\mathrm{EOC}-1 \mathrm{x}$ experiment) in order to estimate its impact on resulting $\delta^{18} \mathrm{O}_{\mathrm{c}}$.

We use present-day orbital parameters, which is a standard technique for deeptime paleoclimate modeling studies, given that we provide snapshots to illustrate the climatic state during the Eocene period and do not focus on representing transient climates due to orbital variations. However, in some other studies, it has been shown that such variations may have a significant impact on the hydrological cycle over Asia $(24,25)$. In order to address this issue, we have tested the impact of orbital parameters variations on the isotopic composition of precipitation with a series of additional paleo-climate experiments (fig. S4, B and C, EOC-CO and EOC-WO experiments). In these experiments, we test two extreme orbital configurations for the Eocene case in order to produce either (i) "warm austral" orbit (or "cold boreal" orbit), with eccentricity 0.05 , obliquity 24.5 , and Earth at perihelion in January (EOC-CO) and (ii) a cold austral summer (and thus a "warm boreal" summer), with eccentricity 0.05 , obliquity 22.5, and Earth at perihelion in July (EOC-WO). Despite some differences in simulated MJJAS precipitation amounts 
Fig. 6. Maps of $\delta^{18} \mathrm{O}_{\mathrm{c}}$ calculated from model simulated MJJAS precipitationweighted $\delta^{18} \mathrm{O}_{\mathrm{w}}$ and model MJJAS mean temperatures for Eocene cases.

(A) EOC-L. (B) EOCHim. (C) EOC-M.

(D) EOC-sea.

(E) EOC-North.

(F) EOC-South. For all Eocene maps, points show measured $\delta^{18} \mathrm{O}_{c}$ from published data sets, consisting of the most negative values for lacustrine carbonates and average values for paleosols (Table 1).
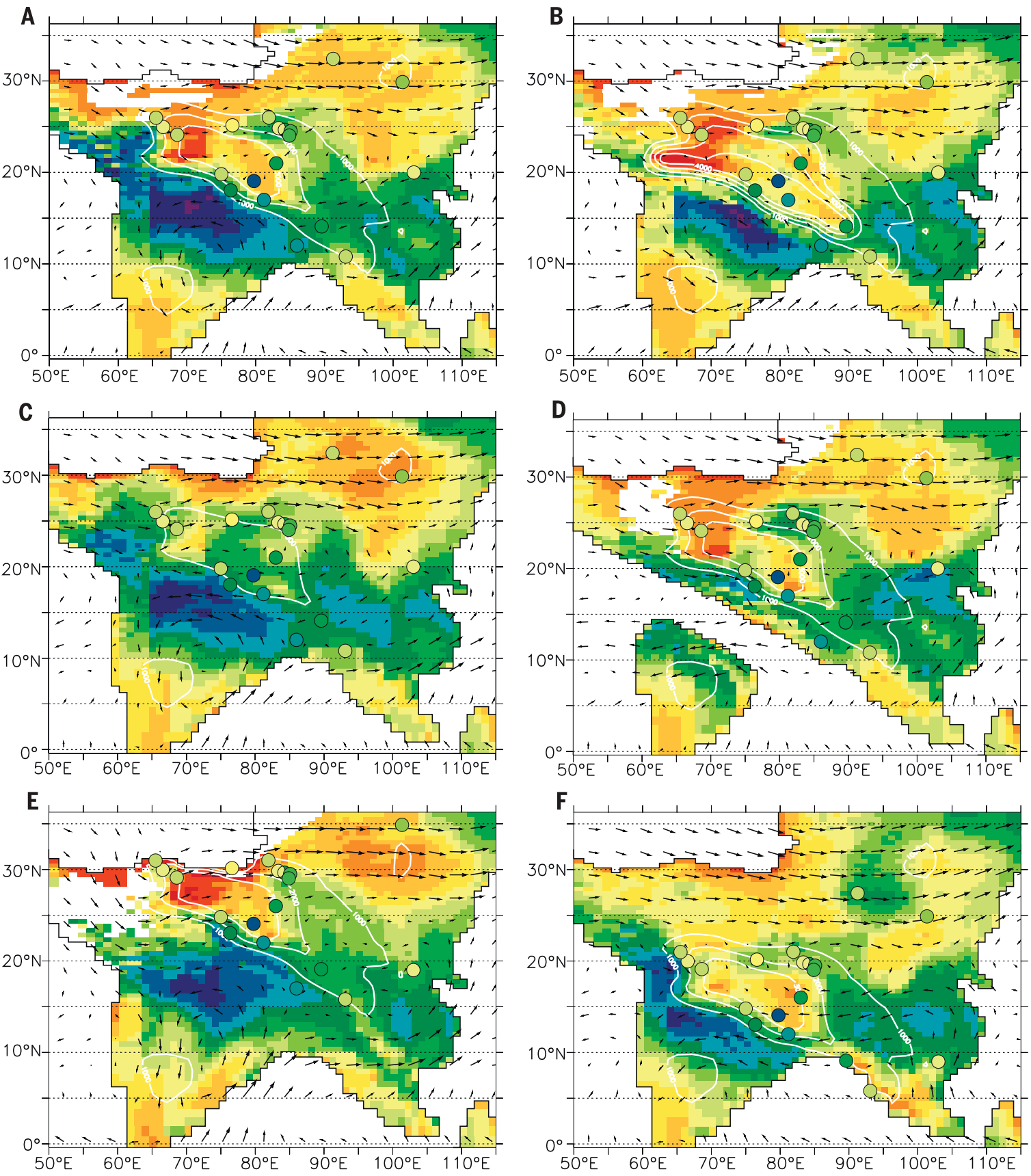

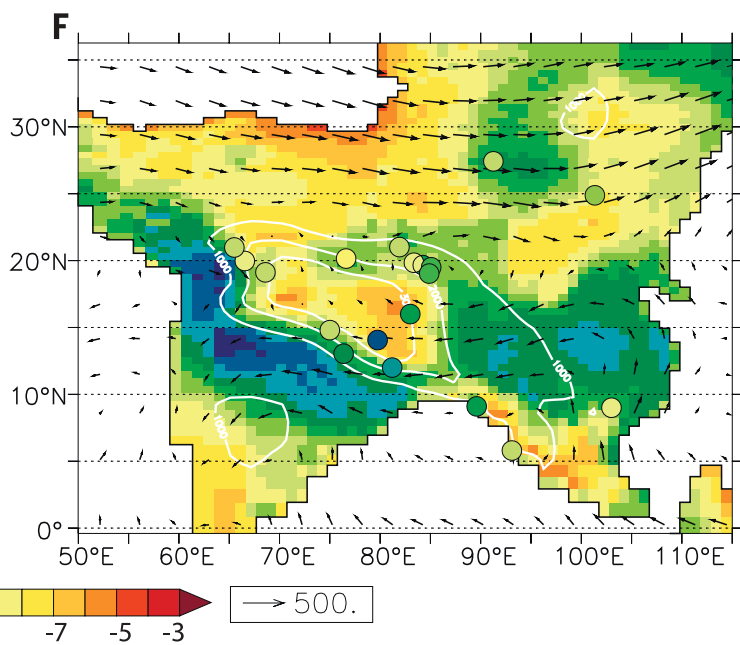

for these "warm boreal" and "cold boreal" scenarios, $\delta^{18} \mathrm{O}_{\mathrm{p}}$ summer [May, June, July, August, and September (MJJAS)] patterns appear to be fairly similar for the three orbital forcings tested here. For all cases, more negative values of $\delta^{18} \mathrm{O}_{\mathrm{p}}$ are simulated over India and the southern slopes of the HTP, while an area between $20^{\circ} \mathrm{N}$ and $40^{\circ} \mathrm{N}$ is characterized by more positive values of $\delta^{18} \mathrm{O}_{\mathrm{p}}$. This gradient is strongest for the "warm boreal" scenario case.

\section{Model-data comparison}

We compare Eocene precipitation-weighted $\delta^{18} \mathrm{O}_{\mathrm{c}}$ derived from our simulations with published
Eocene $\delta^{18} \mathrm{O}_{\mathrm{c}}$ data (Table 1 and Figs. 5 and 6) $(8,10,13,24,57-66)$. Pedogenic carbonates on the TP commonly form during the summer season (67); thus, to derive $\delta^{18} \mathrm{O}_{\mathrm{c}}$ from our simulated $\delta^{18} \mathrm{O}_{\mathrm{w}}$ values, we use May-September mean surface temperatures and use the fractionation factors of (17)

With an objective of adjusting the parameters of a model function $[y=f(x)]$ to best fit a data set (where $x$ is $\delta^{18} \mathrm{O}_{\mathrm{c}}$ from published data sets and $y$ is $\delta^{18} \mathrm{O}_{c}$ simulated by LMDZ-iso), we calculate the sum of squared residuals (SSR) for 20 data points, which permits us to define the optimum model-data fit, which is when the SSR is minimized. For EOC-S and EOC-M simulations, SSR is estimated to be the smallest, 65.8 and 160 respectively, while EOC-XL and EOCHim simulations show the highest values, 369.7 and 453.63 respectively. SSR for the EOC-sea experiment is comparable with those for the EOC-L experiment and both EOC-North and EOC-south show relatively high SSR similar to the EOC-Him case. Note that for SSR calculation for the EOC-North and EOC-South, we have adjusted the location of the data points $5^{\circ}$ to the south and to the north respectively. The difference in the SSR between two different elevations scenarios is larger than the 
difference attributable to the variability in the $\delta^{18} \mathrm{O}$ dataset (Table 1). Consequently, we dismiss variability in the carbonate $\delta^{18} \mathrm{O}$ as excluding the firm conclusions that the best data-model match is with lower elevation scenarios.

\section{Uncertainties and limits of our modeling approach}

A major uncertainty in this study is due to the reconstruction of the geographical position of each site's $\delta^{18} \mathrm{O}_{\mathrm{c}}$ data during Eocene. Based on paleomagnetic data for the Hoh Xil Basin (modern coordinates: $\left.34.60^{\circ} \mathrm{N}, 93^{\circ} \mathrm{E}\right)(68)$, we reconstruct its Eocene paleolatitude as approximately $21^{\circ} \mathrm{N}$ (as a result of northward convergence of the Hoh Xil Basin with respect to Eurasia (Siberia) since Early Eocene-Late Oligocene time). Thus, we use a constant correction of $13^{\circ}$ for positioning all of the geologic $\delta^{18} \mathrm{O}$ sampling sites over our Eocene paleogeography. Such paleoaltitude estimates and corrections of about $13 \pm 5^{\circ}$ are in general consistent with the palaeolatitudes derived from a large number of highquality palaeomagnetic studies from eastern China to Kyrgyzstan (23).

Though GCMs produce realistic Eocene temperatures over Asia and simulate the associated response of $\delta^{18} \mathrm{O}_{\mathrm{w}}$, numerical modeling with GCMs involves several uncertainties, including the assumption of constant seawater $\delta^{18} \mathrm{O}$ and the accuracy of the paleogeographic reconstruction. The latitudinal position of the Indian subcontinent in the Eocene and the height of other orogens in Asia, as well as their spatial extent, remain a point of contention $(23,69)$ and may impact the results of our experiments. To address this limitation, additional paleogeographic scenarios should be tested in future work. Other potential limitations of using isotope-enabled GCMs include complexity associated with our representation of soils, evapotranspiration, and vegetation. However, results of our current study permit a first-order estimate of Eocene $\delta^{18} \mathrm{O}_{\mathrm{w}}$ and its low sensitivity to topographic change.

\section{Decomposing $\delta^{18} \mathrm{O}_{c}$ differences}

Our goal is to understand to what extent $\delta^{18} \mathrm{O}_{\mathrm{w}}$ changes explain the $\delta^{18} \mathrm{O}_{\mathrm{c}}$ signal over the Eocene TP and what part of this signal depends on the temperature of carbonate formation. First, based on an assumption of equilibrium between water and calcite, we relate $\delta^{18} \mathrm{O}_{\mathrm{c}}$ to $\delta^{18} \mathrm{O}_{\mathrm{w}}$ using the relationship of (17)

$$
\begin{gathered}
R_{\mathrm{c}}=R_{\mathrm{w}} / 1.0309-29.98+17.49^{*} 1000 / \\
T-31.45
\end{gathered}
$$

where $T$ is the temperature of carbonate formation, $R_{\mathrm{c}}$ is the isotopic ratios in carbonate, and $R_{\mathrm{w}}$ is the isotopic ratios in paleo surface water, or in a simpler form

$$
R_{\mathrm{c}}=R_{\mathrm{c}}\left(R_{\mathrm{w}}, T\right)
$$

In order to understand why $R_{\mathrm{w}}$ varies from one climatic state to another, we decompose $\Delta R_{\mathrm{c}}=R_{\mathrm{c} 2}-R_{\mathrm{c} 1}$ into contribution from $\mathrm{d} R_{\mathrm{w}}$ and $\mathrm{d} T$ terms, referring to the climatic states using subscript 1 and 2 and to their difference using the $\Delta$ notation

$$
\Delta R_{\mathrm{c}}=\Delta R_{\mathrm{c}, \mathrm{d} R \mathrm{w}}+\Delta R_{\mathrm{c}, \mathrm{d} T}+N
$$

where $\Delta R_{\mathrm{c}, \mathrm{d} R \mathrm{w}}$ and $\Delta R_{\mathrm{c}, \mathrm{dT}}$ are the contributions of the part of the $R_{\mathrm{c}}$ signal related to the change of $R_{\mathrm{w}}$ and temperature accordingly. Nonlinear terms of decomposition are gathered into the residual term $N$.

Similar to the isotopic signal decomposition suggested in (20), contributions could be estimated as

$$
\Delta R_{\mathrm{c}, \mathrm{d} R \mathrm{w}}=R_{\mathrm{c}}\left(R_{\mathrm{w} 2}, \mathrm{~d} T^{\prime}\right)-R_{\mathrm{c}}\left(R_{\mathrm{w} 1}, \mathrm{~d} T^{\prime}\right)
$$

and

$$
\Delta R_{\mathrm{c}, \mathrm{d} T}=R_{\mathrm{c}}\left(\mathrm{d} R_{\mathrm{w}}{ }^{\prime}, T_{2}\right)-R_{\mathrm{c}}\left(\mathrm{d} R_{\mathrm{w}}{ }^{\prime}, T_{1}\right)
$$

where $R_{\mathrm{w} 2}, R_{\mathrm{w} 1}, T_{2}$, and $T_{1}$ are $\delta^{18} \mathrm{O}_{\mathrm{w}}$ and temperature from two climatic states, respectively, and $\mathrm{d} R_{\mathrm{w}}{ }^{\prime}, \mathrm{d} T^{\prime}$ are centered differences

$$
\begin{gathered}
\mathrm{d} R_{\mathrm{w}}{ }^{\prime}=\left(R_{\mathrm{w} 1}+R_{\mathrm{w} 2}\right) / 2 \\
\mathrm{~d} T^{\prime}=\left(T_{1}+T_{2}\right) / 2
\end{gathered}
$$

From the Eqs. 1, 3, 4, and 5, we have

$$
\begin{gathered}
\Delta R_{\mathrm{c}, \mathrm{d} R \mathrm{w}}=\left(R_{\mathrm{w} 2}-R_{\mathrm{w} 1}\right) / 1.0309 \\
\Delta R_{\mathrm{c}, \mathrm{d} T}=17.49 *\left(1000 / T_{2}-1000 / T_{1}\right) \\
N=\Delta R_{\mathrm{c}}-\left(\Delta R_{\mathrm{c}, \mathrm{d} R \mathrm{w}}+\Delta R_{\mathrm{c}, \mathrm{d} T}\right)
\end{gathered}
$$

\section{REFERENCES AND NOTES}

1. P. Molnar, P. England, J. Martinod, Mantle dynamics, uplift of the Tibetan Plateau, and the Indian monsoon. Rev. Geophys. 31. 357-396 (1993). doi: 10.1029/93RG02030

2. M. E. Raymo, W. F. Ruddiman, Tectonic forcing of late Cenozoic climate. Nature 359, 117-122 (1992). doi: 10.1038/ $359117 \mathrm{a} 0$

3. M. Ingalls, D. B. Rowley, B. Currie, A. S. Colman, Large-scale subduction of continental crust implied by India-Asia massbalance calculation. Nat. Geosci. 9, 848-853 (2016). doi: $10.1038 /$ ngeo2806

4. C. Wang et al., Outward-growth of the Tibetan Plateau during the Cenozoic: A review. Tectonophysics 621, 1-43 (2014). doi: 10.1016/j.tecto.2014.01.036

5. M. A. Murphy et al., Did the Indo-Asian collision alone create the Tibetan plateau? Geology 25, 719-722 (1997). doi: 10.1130/0091-7613(1997)025<0719:DTIACA>2.3.C0;2

6. P. Tapponnier et al., Oblique stepwise rise and growth of the Tibet plateau. Science 294, 1671-1677 (2001). doi: 10.1126/ science.105978; pmid: 11721044

7. D. Zheng et al., Rapid exhumation at $\sim 8 \mathrm{Ma}$ on the Liupan Shan thrust fault from apatite fission-track thermochronology: Implications for growth of the northeastern Tibetan Plateau margin. Earth Planet. Sci. Lett. 248, 198-208 (2006). doi: 10.1016/j.epsl.2006.05.023

8. D. B. Rowley, B. S. Currie, Palaeo-altimetry of the late Eocene to Miocene Lunpola basin, central Tibet. Nature 439, 677-681 (2006). doi: 10.1038/nature04506; pmid: 16467830

9. 0 . Xu et al.. Paleogene high elevations in the Qiangtang Terrane, central Tibetan Plateau. Earth Planet. Sci. Lett. 362 31-42 (2013). doi: 10.1016/j.epsl.2012.11.058

10. L. Ding et al., The Andean-type Gangdese Mountains: Paleoelevation record from the Paleocene-Eocene Linzhou Basin. Earth Planet. Sci. Lett. 392, 250-264 (2014) doi: 10.1016/j.epsl.2014.01.045
11. X. Y. Song, R. A. Spicer, J. Yang, Y. F. Yao, C.-S. Li, Pollen evidence for an Eocene to Miocene elevation of central southern Tibet predating the rise of the High Himalaya. Palaeogeogr. Palaeoclimatol. Palaeoecol. 297, 159-168 (2010). doi: 10.1016/j.palaeo.2010.07.025

12. H. Wang et al., Amber fossils reveal the Early Cenozoic dipterocarp rainforest in central Tibet. Palaeoworld 27 506-513 (2018). doi: 10.1016/j.palwor.2018.09.006

13. Y. Wei et al., Low palaeoelevation of the northern Lhasa terrane during late Eocene: Fossil foraminifera and stable isotope evidence from the Gerze Basin. Sci. Rep. 6, 27508 (2016) doi: 10.1038/srep27508; pmid: 27272610

14. F. Wu, D. Miao, M. M. Chang, G. Shi, N. Wang, Fossil climbing perch and associated plant megafossils indicate a warm and wet central Tibet during the late Oligocene. Sci. Rep. 7, 878 (2017). pmid: 28408764

15. D. B. Rowley, R. T. Pierrehumbert, B. S. Currie, A new approach to stable isotope-based paleoaltimetry: Implications for paleoaltimetry and paleohypsometry of the High Himalaya since the late Miocene. Earth Planet. Sci. Lett. 188, 253-268 (2001). doi: 10.1016/S0012-821X(01)00324-7

16. J. Quade, D. 0. Breecker, M. Daëron, J. Eiler, The paleoaltimetry of Tibet: An isotopic perspective. Am. J. Sci. 311, 77-115 (2011). doi: 10.2475/02.2011.01

17. S. T. Kim, J. R. O'Neil, Equilibrium and nonequilibrium oxygen isotope effects in synthetic carbonates. Geochim. Cosmochim. Acta 61, 3461-3475 (1997). doi: 10.1016/S0016-7037(97) 00169-5

18. C. J. Poulsen, M. L. Jeffery, Climate change imprinting on stable isotopic compositions of high-elevation meteoric water cloaks past surface elevations of major orogens. Geology 39 , 595-598 (2011). doi: 10.1130/G32052.1

19. M. J. Winnick, C. P. Chamberlain, J. K. Caves, J. M. Welker, Quantifying the isotopic "continental effect". Earth Planet. Sci. Lett. 406, 123-133 (2014). doi: 10.1016/i.epsl.2014.09.005

20. S. Botsyun, P. Sepulchre, C. Risi, Y. Donnadieu, Impacts of Tibetan Plateau uplift on atmospheric dynamics and associated precipitation $\delta^{18}$ 0. Clim. Past 12, 1401-1420 (2016). doi: 10.5194/cp-12-1401-2016

21. E. Anagnostou et al., Changing atmospheric $\mathrm{CO} 2$ concentration was the primary driver of early Cenozoic climate. Nature 533, 380-384 (2016). doi: 10.1038/ nature17423; pmid: 27111509

22. R. Bosboom et al., Timing, cause and impact of the late Eocene stepwise sea retreat from the Tarim Basin (west China). Palaeogeogr. Palaeoclimatol. Palaeoecol. 403, 101-118 (2014). doi: 10.1016/j.palaeo.2014.03.035

23. P. C. Lippert, D. J. J. van Hinsbergen, G. Dupont-Nivet, Early Cretaceous to present latitude of the central proto-Tibetan Plateau: A paleomagnetic synthesis with implications for Cenozoic tectonics, paleogeography, and climate of Asia. Spec. Pap. Geol. Soc. Am. 2507, 1-21 (2014).

24. A. Licht et al., Asian monsoons in a late Eocene greenhouse world. Nature 513, 501-506 (2014). doi: 10.1038/nature13704; pmid: 25219854

25. R. Zhang et al., Changes in Tibetan Plateau latitude as an important factor for understanding East Asian climate since the Eocene: A modeling study. Earth Planet. Sci. Lett. 484 , 295-308 (2018). doi: 10.1016/j.epsl.2017.12.034

26. J. E. Kutzbach, P. J. Guetter, W. F. Ruddiman, W. L. Prell, Sensitivity of climate to late Cenozoic uplift in southern Asia and the American west: Numerical experiments. J. Geophys. Res. Atmos. 94 (D15), 18393-18407 (1989). doi: 10.1029/ JD094iD15p18393

27. A. J. Broccoli, S. Manabe, The effects of orography on midlatitude northern hemisphere dry climates. J. Clim. 5 1181-1201 (1992). doi: 10.1175/1520-0442(1992)005<1181 TEOOOM>2.0.CO;

28. X. Liu, Z. Y. Yin, Sensitivity of East Asian monsoon climate to the uplift of the Tibetan Plateau. Palaeogeogr. Palaeoclimatol. Palaeoecol. 183, 223-245 (2002). doi: 10.1016/S0031-0182 (01)00488-6

29. D. B. Rowley, C. N. Garzione, Stable isotope-based paleoaltimetry. Annu. Rev. Earth Planet. Sci. 35, 463-508 (2007). doi: 10.1146/annurev.earth.35.031306.140155

30. C. N. Garzione, J. Quade, P. G. DeCelles, N. B. English, Predicting paleoelevation of Tibet and the Himalaya from $\delta^{18} 0$ vs. altitude gradients in meteoric water across the Nepal Himalaya. Earth Planet. Sci. Lett. 183, 215-229 (2000) doi: 10.1016/S0012-821X(00)00252-1

31. J. Worden, D. Noone, K. Bowman, Tropospheric Emission Spectrometer Science Team and Data contributors, Importance of rain evaporation and continental convection in 
the tropical water cycle. Nature 445, 528-532 (2007) doi: 10.1038/nature05508; pmid: 17268467

32. P. K. Aggarwal et al., Proportions of convective and stratiform precipitation revealed in water isotope ratios. Nat. Geosci. 9 , 624-629 (2016). doi: 10.1038/ngeo2739

33. N. Kurita et al., Intraseasonal isotopic variation associated with the Madden-Julian Oscillation. J. Geophys. Res. Atmos. 116 D24101 (2011). doi: 10.1029/2010JD015209

34. O. A. Tuinenburg et al., J. Geophys. Res. Atmos. 10.1002/ 2015JD023461 (2015). doi: 10.1002/2015JD023461

35. N. E. Levin, E. J. Zipser, T. E. Cerling, Isotopic composition of waters from Ethiopia and Kenya: Insights into moisture sources for eastern Africa. J. Geophys. Res. Atmos. 114 D23306 (2009). doi: 10.1029/2009JD012166

36. A. Rohrmann et al., Can stable isotopes ride out the storms? The role of convection for water isotopes in models, records, and paleoaltimetry studies in the central Andes. Earth Planet. Sci. Lett. 407, 187-195 (2014). doi: 10.1016/ j.epsl.2014.09.021

37. J. K. Caves et al., Role of the westerlies in Central Asia climate over the Cenozoic. Earth Planet. Sci. Lett. 428, 33-43 (2015) doi: 10.1016/j.epsl.2015.07.023

38. A. Licht et al., Resilience of the Asian atmospheric circulation shown by Paleogene dust provenance. Nat. Commun. 7, 12390 (2016). doi: 10.1038/ncomms12390; pmid: 27488503

39. C. Risi, S. Bony, F. Vimeux, J. Jouzel, Water-stable isotopes in the LMDZ4 general circulation model: Model evaluation for present-day and past climates and applications to climatic interpretations of tropical isotopic records. J. Geophys. Res. Atmos. 115 (D24), 1-27 (2010). doi: 10.1029/2010JD015242

40. F. Hourdin et al., The LMDZ4 general circulation model: Climate performance and sensitivity to parametrized physics with emphasis on tropical convection. Clim. Dyn. 27, 787-813 (2006). doi: 10.1007/s00382-006-0158-0

41. K. E. Taylor, R. J. Stouffer, G. A. Meehl, An overview of CMIP5 and the experiment design. Bull. Am. Meteorol. Soc. 93, 485-498 (2012). doi: 10.1175/BAMS-D-11-00094.1

42. J. E. Lee et al., Asian monsoon hydrometeorology from TES and SCIAMACHY water vapor isotope measurements and LMDZ simulations: Implications for speleothem climate record interpretation. J. Geophys. Res. Atmos. 117, 1-12 (2012). doi: 10.1029/2011JD017133

43. R. Krishnan et al., Deciphering the desiccation trend of the South Asian monsoon hydroclimate in a warming world. Clim. Dyn. 10.1007/s00382-015-2886-5 (2015). doi: 10.1007/ s00382-015-2886-5

44. J.-B. Ladant, Y. Donnadieu, V. Lefebvre, C. Dumas, The respective role of atmospheric carbon dioxide and orbital parameters on ice sheet evolution at the Eocene-Oligocene transition. Paleoceanography 29, 810-823 (2014). doi: 10.1002/2013PA002593

45. S. Bony, C. Risi, F. Vimeux, Influence of convective processes on the isotopic composition $\left(\delta^{18} 0\right.$ and $\left.\delta D\right)$ of precipitation and water vapor in the tropics: 1 . Radiative-convective equilibrium and Tropical Ocean-Global-Atmosphere-Coupled OceanAtmosphere Responce Experiment (TOGA-COARE). J. Geophys. Res. Atmos. 113, D19305 (2008). doi: 10.1029/ 2008JD009942

46. B. Van Leer, Towards the ultimate conservative difference scheme. IV. A new approach to numerical convection. J. Comput. Phys. 23, 276-299 (1977). doi: 10.1016/0021 9991(77)90095-X
47. L. Merlivat, G. Nief, Fractionnement isotopique lors des changements d'état solide-vapeur et liquide-vapeur de l'eau à des températures inférieures à $0^{\circ} \mathrm{C}$. Tellus 19, 122-127 (1967). doi: 10.3402/tellusa.v19i1.9756

48. M. Majoube, Fractionnement en oxygene-18 et en deuterium entre l'eau et sa vapeur. J. Chim. Phys. 68, 1423-1436 (1971). doi: 10.1051/jcp/1971681423

49. L. Merlivat, J. Jouzel, Global climatic interpretation of the deuterium-oxygen 18 relationship for precipitation. J. Geophys. Res. Oceans 84 (C8), 5029-5033 (1979). doi: 10.1029/ JC084iC08p05029

50. J. Jouzel, L. Merlivat, Deuterium and oxygen 18 in precipitation: Modeling of the isotopic effects during snow formation. J. Geophys. Res. Atmos. 89 (D7), 11749-11757 (1984) doi: 10.1029/JD089iD07p11749

51. J. E. Lee, I. Fung, "Amount effect" of water isotopes and quantitative analysis of post-condensation processes. Hydrol. Processes 22, 1-8 (2008). doi: 10.1002/hyp.6637

52. R. L. Jacob, Low frequency variability in a simulated atmosphere ocean system, thesis, University of Wisconsin, Madison, WI (1997).

53. S. Sitch et al., Evaluation of ecosystem dynamics, plant geography and terrestrial carbon cycling in the LPJ dynamic global vegetation model. Glob. Change Biol. 9, 161-185 (2003). doi: 10.1046/j.1365-2486.2003.00569.x

54. Y. Donnadieu, E. Pucéat, M. Moiroud, F. Guillocheau, J.-F. Deconinck, A better-ventilated ocean triggered by Late Cretaceous changes in continental configuration. Nat. Commun. 7, 10316 (2016). doi: 10.1038/ncomms10316; pmid: 26777897

55. M. Baatsen et al., Equilibrium state and sensitivity of the simulated middle-to-late Eocene climate. Clim. Past Discuss. 1-49 (2018). doi: 10.5194/cp-2018-43

56. D. K. Hutchinson et al., Climate sensitivity and meridional overturning circulation in the late Eocene using GFDL CM2.1. Clim. Past 14, 789-810 (2018). doi: 10.5194/cp-14-789-2018

57. M. T. Hren, B. Bookhagen, P. M. Blisniuk, A. L. Booth, C. P. Chamberlain, $\delta 180$ and $\delta \mathrm{D}$ of streamwaters across the Himalaya and Tibetan Plateau: Implications for moisture sources and paleoelevation reconstructions. Earth Planet. Sci. Lett. 288, 20-32 (2009). doi: 10.1016/ j.epsl.2009.08.041

58. J. Bershaw, S. M. Penny, C. N. Garzione, Stable isotopes of modern water across the Himalaya and eastern Tibetan Plateau: Implications for estimates of paleoelevation and paleoclimate. J. Geophys. Res. Atmos. 117, 1-18 (2012). doi: 10.1029/2011JD016132

59. J. Bershaw, C. N. Garzione, L. Schoenbohm, G. Gehrels, L. Tao, Cenozoic evolution of the Pamir plateau based on stratigraphy, zircon provenance, and stable isotopes of foreland basin sediments at Oytag (Wuyitake) in the Tarim Basin (west China). J. Asian Earth Sci. 44, 136-148 (2012). doi: 10.1016/ j.jseaes.2011.04.020

60. M. L. Kent-Corson et al., Stable isotopic constraints on the tectonic, topographic, and climatic evolution of the northern margin of the Tibetan Plateau. Earth Planet. Sci. Lett. 282 158-166 (2009). doi: 10.1016/j.epsl.2009.03.011

61. G. D. Hoke, J. Liu-Zeng, M. T. Hren, G. K. Wissink, C. N. Garzione, Stable isotopes reveal high southeast Tibetan Plateau margin since the Paleogene. Earth Planet. Sci. Lett. 394, 270-278 (2014). doi: 10.1016/j.epsl.2014.03.007

62. G. J. Bowen, P. L. Koch, J. Meng, J. Ye, S. Ting, Age and Correlation of Fossiliferous Late Paleocene-Early Eocene
Strata of the Erlian Basin, Inner Mongolia, China. Am. Mus. Novit. 3474, 1 (2005). doi: 10.1206/0003-0082(2005)474 [0001:AACOFL]2.0.C0;2

63. S. Ting et al., Biostratigraphic, chemostratigraphic, and magnetostratigraphic study across the Paleocene-Eocene boundary in the Hengyang Basin, Hunan, China. Geol. Soc. Am. Spacial Pa, 521-535 (2003)

64. A. J. Cyr, B. S. Currie, D. B. Rowley, Geochemical evaluation of Fenghuoshan group lacustrine carbonates, north-central Tibet: Implications for the paleoaltimetry of the Eocene Tibetan Plateau. J. Geol. 113, 517-533 (2005). doi: 10.1086/ 431907

65. J. K. Caves, D. J. Sjostrom, H. T. Mix, M. J. Winnick, C. P. Chamberlain, Aridification of Central Asia and uplift of the Altai and Hangay Mountains, Mongolia: Stable isotope evidence. Am. J. Sci. 314, 1171-1201 (2014). doi: 10.2475/ 08.2014 .01

66. Q. Xu, L. Ding, R. Hetzel, Y. Yue, E. F. Rades, Low elevation of the northern Lhasa terrane in the Eocene: Implications for relief development in south Tibet. Terra 27, 458-466 (2015).

67. J. Quade, J. Eiler, M. Daeron, H. Achyuthan, The clumped isotope geothermometer in soil and paleosol carbonate. Geochim. Cosmochim. Acta 105, 92-107 (2013). doi: 10.1016/ j.gca.2012.11.031

68. Z. Liu, X. Zhao, C. Wang, S. Liu, H. Yi, Magnetostratigraphy of Tertiary sediments from the Hoh Xil Basin: Implications for the Cenozoic tectonic history of the Tibetan Plateau. Geophys. J. Int. 154, 233-252 (2003). doi: 10.1046/ j.1365-246X.2003.01986.x

69. Y. Najman et al., Timing of India-Asia collision: Geological, biostratigraphic, and palaeomagnetic constraints. J. Geophys. Res. Solid Earth 115, B12416 (2010). doi: 10.1029/ 2010JB007673

70. GNIP, IAEA/WMO, Global Network of Isotopes in Precipitation: The GNIP Database; www.iaea.org/services/networks/gnip. (2016)

\section{ACKNOWLEDGMENTS}

Funding: This work was funded by the FP7-PEOPLE: Marie-Curie Actions [grant 316966, iTECC (interaction Tectonics-ErosionClimate-Coupling) project]. This work was granted access to the HPC resources of IDRIS under the allocation 2017-0292 made by GENCl. S.B. was also supported by the German Ministry for Education and Research (BMBF) grant 03T0863A to T. Ehlers. J.K.C.R. is funded by an ETH Fellowship. Author contributions: S.B., P.S., and Y.D. developed the conceptual idea. S.B. designed and carried out simulations in close collaboration with P.S., C.R., and Y.D.; J.K.C.R. and S.B. did statistical analysis. S.B., A.L., and J.K.C.R. analyzed observed carbonate data. All authors discussed the results and implications and commented on the manuscript. Competing interests: None declared. Data and materials availability: All data are available in the manuscript or in the supplementary materials.

\section{SUPPLEMENTARY MATERIALS}

www.sciencemag.org/content/363/6430/eaaq1436/suppl/DC1 Figs. S1 to S12

5 October 2017; resubmitted 6 September 2018

Accepted 22 January 2019

10.1126/science.aaq1436 


\section{Science}

\section{Revised paleoaltimetry data show low Tibetan Plateau elevation during the Eocene}

Svetlana Botsyun, Pierre Sepulchre, Yannick Donnadieu, Camille Risi, Alexis Licht and Jeremy K. Caves Rugenstein

Science 363 (6430), eaaq1436.

DOI: $10.1126 /$ science.aaq1436

\section{Ancient height of the Tibetan Plateau}

The elevation of the Tibetan Plateau has a major impact on climate, affecting the monsoons and regional weather patterns. Although some isotope proxies have suggested a roughly equivalent height for the plateau as far back as the Eocene ( 40 million years ago), other lines of evidence suggest a lower elevation in the distant past. Botsyun et al. used a model to show that several previously overlooked factors contribute to the isotopic record from the Eocene (see the Perspective by van Hinsbergen and Boschman). The results harmonize the isotopic record with other proxies and argue for a Tibetan Plateau that was about 1000 meters lower than it is today.

Science, this issue p. eaaq1436; see also p. 928

ARTICLE TOOLS

SUPPLEMENTARY MATERIALS

RELATED

REFERENCES

PERMISSIONS http://science.sciencemag.org/content/363/6430/eaaq1436

http://science.sciencemag.org/content/suppl/2019/02/27/363.6430.eaaq1436.DC1

http://science.sciencemag.org/content/sci/363/6430/928.full

This article cites 67 articles, 5 of which you can access for free http://science.sciencemag.org/content/363/6430/eaaq1436\#BIBL

http://www.sciencemag.org/help/reprints-and-permissions

Use of this article is subject to the Terms of Service

Science (print ISSN 0036-8075; online ISSN 1095-9203) is published by the American Association for the Advancement of Science, 1200 New York Avenue NW, Washington, DC 20005. The title Science is a registered trademark of AAAS.

Copyright (C) 2019 The Authors, some rights reserved; exclusive licensee American Association for the Advancement of Science. No claim to original U.S. Government Works 